\title{
Adenocarcinoma of the small instestine
}

INSERM

\section{Source}

INSERM. (1999). Orphanet: an online rare disease and orphan drug data base.

Adenocarcinoma of the small instestine. ORPHA:104075

Small bowel adenocarcinoma (SBA) is a rare small intestinal malignancy, most commonly located in the duodenum (55\% of cases) but also rarely in the jejunum and ileum, which is usually discovered at an advanced stage in the 6th to 7th decade of life due to nonspecific symptoms at presentation such as nausea, abdominal pain and weight loss. In some cases it is asymptomatic, and therefore usually has a poor prognosis. 